\title{
Pleiotropic effect of the ABCG2 gene in gout: involvement in serum urate levels and progression from hyperuricemia to gout
}

Rebekah Wrigley ${ }^{1 \dagger}$, Amanda J. Phipps-Green ${ }^{1 \dagger}$, Ruth K. Topless ${ }^{1}$, Tanya J. Major ${ }^{1}$, Murray Cadzow ${ }^{1}$, Philip Riches², Anne-Kathrin Tausche ${ }^{3}$, Matthijs Janssen ${ }^{4}$, Leo A. B. Joosten ${ }^{5,6}$, Tim L. Jansen ${ }^{4}$, Alexander So ${ }^{7}$, Jennie Harré Hindmarsh ${ }^{8}$, Lisa K. Stamp ${ }^{9}$, Nicola Dalbeth ${ }^{10}$ and Tony R. Merriman ${ }^{1 *}$ (D)

\begin{abstract}
Background: The ABCG2 Q141K (rs2231142) and rs 10011796 variants associate with hyperuricaemia (HU). The effect size of $A B C G 2$ rs 2231142 on urate is $~ 60 \%$ that of SLC2A9, yet the effect size on gout is greater. We tested the hypothesis that $A B C G 2$ plays a role in the progression from $\mathrm{HU}$ to gout by testing for association of $A B C G 2$ rs2231142 and rs10011796 with gout using HU controls.

Methods: We analysed 1699 European gout cases and 14,350 normouricemic (NU) and HU controls, and 912 New Zealand (NZ) Polynesian (divided into Eastern and Western Polynesian) gout cases and 696 controls. Association testing was performed using logistic and linear regression with multivariate adjusting for confounding variables.

Results: In Europeans and Polynesians, the $A B C G 2141 \mathrm{~K}$ (T) allele was associated with gout using HU controls (OR= $1.85, P=3.8 \mathrm{E}^{-21}$ and $\mathrm{OR}_{\text {meta }}=1.85, P=1.3 \mathrm{E}^{-03}$, respectively). There was evidence for an effect of $141 \mathrm{~K}$ in determining $\mathrm{HU}$ in European $\left(\mathrm{OR}=1.56, P=1.7 \mathrm{E}^{-18}\right)$ but not in Polynesian $\left(\mathrm{OR}_{\text {meta }}=1.49, P=0.057\right)$. For SLC2A9 rs 11942223, the T allele associated with gout in the presence of $\mathrm{HU}$ in European $\left(\mathrm{OR}=1.37, P=4.7 \mathrm{E}^{-06}\right)$, however significantly weaker than $A B C G 2$ rs $2231142141 \mathrm{~K}\left(P_{\text {Het }}=0.0023\right)$. In Western Polynesian and European, there was epistatic interaction between $A B C G 2$ rs2231142 and rs 10011796. Combining the presence of the $141 \mathrm{~K}$ allele with the rs 10011796 CC-genotype increased gout risk, in the presence of HU, 21.5-fold in Western Polynesian $(P=0.009)$ and 2.6-fold in European $\left(P=9.9 \mathrm{E}^{-06}\right)$. The $141 \mathrm{~K}$ allele of $A B C G 2$ associated with increased gout flare frequency in Polynesian $\left(P_{\text {meta }}=2.5 \mathrm{E}^{-03}\right)$.
\end{abstract}

Conclusion: These data are consistent with a role for $A B C G 2141 \mathrm{~K}$ in gout in the presence of established HU. Keywords: Gout, Urate, Hyperuricemia, ABCG2, Association, Polymorphism

* Correspondence: tony.merriman@otago.ac.nz

${ }^{\dagger}$ Rebekah Wrigley and Amanda J. Phipps-Green contributed equally to this work.

${ }^{1}$ Department of Biochemistry, University of Otago, Box 56, Dunedin, New Zealand

Full list of author information is available at the end of the article

\section{Introduction}

The pathogenesis of gout is thought to require progression through three checkpoints: hyperuricaemia (HU), deposition of monosodium urate (MSU) crystals into articular and peri-articular structures, and an inflammatory response to these crystals [1]. Genome-wide association studies (GWAS) have emphasised the contribution

(c) The Author(s). 2020 Open Access This article is licensed under a Creative Commons Attribution 4.0 International License, which permits use, sharing, adaptation, distribution and reproduction in any medium or format, as long as you give appropriate credit to the original author(s) and the source, provide a link to the Creative Commons licence, and indicate if changes were made. The images or other third party material in this article are included in the article's Creative Commons licence, unless indicated otherwise in a credit line to the material. If material is not included in the article's Creative Commons licence and your intended use is not permitted by statutory regulation or exceeds the permitted use, you will need to obtain permission directly from the copyright holder. To view a copy of this licence, visit http://creativecommons.org/licenses/by/4.0/ The Creative Commons Public Domain Dedication waiver (http://creativecommons.org/publicdomain/zero/1.0/) applies to the data made available in this article, unless otherwise stated in a credit line to the data. 
to urate control of genetic variation in renal and gut urate transporters, including $S L C 2 A 9$ and $A B C G 2[2,3]$. When combined, variants in these two genes explain $3-4 \%$ of variance in urate levels and have strong effects on the risk of gout $[4,5]$. However, understanding of pathways regulating MSU crystal deposition and the inflammatory response to deposited crystals in gout remains important because fewer than a quarter of people with HU develop gout [6]. Production of the inflammatory cytokine interleukin-1 $\beta$ (IL-1 $\beta$ ) is central to the inflammatory response to MSU crystals $[7,8]$. The pathway that produces IL- $1 \beta$ involves activation of the NLRP3 inflammasome, resulting in cleavage of pro-IL-1 $\beta$ to mature IL- $1 \beta$ by caspase-1. There is little knowledge, however, about the genetic variants that promote the formation of MSU crystals and initiate the innate immune response in the presence of $\mathrm{HU}$ [9], although variants in the toll-like receptor 4 and components of the NLRP3 inflammasome have been associated with increased risk of gout [10-12].

The $A B C G 2$ gene was first associated with serum urate levels and gout by Dehghan et al. [13]. The encoded protein (also known as breast cancer resistance protein) functions as a urate and oxypurinol transporter in the kidney and gut [14]. The lysine ( $\mathrm{T}$ ) allele of the Q141K (rs2231142) single nucleotide polymorphism (SNP) is associated with $\mathrm{HU}$ and increased risk of gout (reviewed in [14]). This variant decreases gut excretion of urate, contributing to a subtype of HU termed extra-renal under-excretion of urate $[15,16]$. The $141 \mathrm{~K}$ allele is also associated with a poor response to the principal urate-lowering therapy allopurinol (xanthine oxidase inhibitor) in people with gout [17-19]. Wen et al. [17] reported a second genetically independent variant, rs10011796, associated with poor allopurinol response, although this association could not be replicated in a wellphenotyped, allopurinol-compliant sample set [19]. SNP rs10011796 strongly associated with urate in Europeans $\left(\beta=0.089 \mathrm{mg} / \mathrm{dL}, P=2.4 \times 10^{-51}\right)$, albeit with a weaker effect than $r s 2231142\left(\beta=0.221 \mathrm{mg} / \mathrm{dL}, P=4.4 \times 10^{-116}\right)$ [4].

The $141 \mathrm{~K}$ variant creates instability in the protein's nucleotide-binding domain, reducing expression of $A B C G 2$ due to a processing defect and impaired trafficking to the cell membrane [20]. This causes a $50 \%$ reduction of ABCG2-mediated uric acid excretion [21]. Dysfunction can be rescued by low temperature [22], and administration of small ligands, such as histone deacetylase inhibitors and colchicine, an anti-inflammatory drug used on the treatment of gout flares by disrupting neutrophil microtubule functioning $[20,23]$. The defective protein is retained in aggresomes, a cellular pathway activated when proteasome activity is exceeded, and is subsequently degraded by the autophagy pathway [23, 24]. Deficiency in ABCG2 generates dysfunctional mitochondria [25] and reduced copy number of mitochondrial DNA associates with increased risk of gout in NZ Polynesian [26].
The observation that colchicine is able to rescue the $141 \mathrm{~K}$ trafficking defect [23], the proposal that autophagy machinery and the inflammasome interact in the innate immune response [27], and evidence for association of ABCG2 rs 2231142 with gout in the presence of $\mathrm{HU}$ in East Asian populations [28-30], suggests that ABCG2 may be important in gout beyond its established role in elevating urate levels. This hypothesis is further supported by the observation that the effect size of $A B C G 2$ on urate in Europeans and Japanese is $58 \%$ and $73 \%$ that of $S L C 2 A 9$, the most influential urate locus $[4,31]$, respectively, yet the effect size of $A B C G 2$ on gout is consistently larger than that of $S L C 2 A 9$ [4, 5, 32]. Therefore, we tested the hypothesis in European and Aotearoa New Zealand Polynesian (NZ Māori and Pacific Island peoples) that $A B C G 2$ has a role in the progression of $\mathrm{HU}$ to gout using a genetic epidemiological approach by testing for association of ABCG2 rs2231142 and rs10011796 with gout in the presence of $\mathrm{HU}$.

\section{Participants and methods Participants}

The European sample set comprised 1699 participants with gout and 14,350 controls (2422 asymptomatic HU, and 11,928 NU). The NZ Polynesian sample set (individuals of NZ and Cook Island Mãori, Samoan, Tongan, Niuean and Tokelauan ancestry) comprised 912 participants with gout, and 696 controls (202 HU and 494 NU) (Additional file 1). Hyperuricemia was defined, for both sexes, as serum urate $\geq 0.42 \mathrm{mmol} / \mathrm{L}(7 \mathrm{mg} / \mathrm{dL})$.

All people with gout fulfilled the 1977 American Rheumatism Association gout classification criteria [33]. Gout cases were recruited from New Zealand (979 Europeans, 912 Polynesians), Australia and Europe (720 Europeans). The 14,350 European controls (all self-reported as not having physician-diagnosed gout, not having kidney disease and not taking urate-lowering medication) were obtained from five sources: 452 individuals recruited from New Zealand, 6970 participants from the Atherosclerosis Risk in Communities (ARIC) study, 2689 participants from the Framingham Heart Study (FHS), 1492 participants from the Coronary Artery Risk Development in Young Adults (CARDIA) study, and 2747 participants from the Cardiovascular Health Study (CHS). Phenotypes from baseline exams were used for all studies with the exception of CARDIA, where phenotypes from exam six were used. The 696 Polynesian controls were recruited from New Zealand using the same exclusion criteria.

Ancestry for controls from ARIC, FHS, CARDIA and CHS was used as provided in these datasets. Ancestry for the NZ, Australian and European gout cases and the NZ controls was classified based on principal components computed from genome-wide SNP data. The NZ Polynesian sample set was divided into Eastern and Western 
Polynesian ancestral groups based on principal components from genome-wide genotype data [34]. Eastern Polynesian comprised of Cook Island and NZ Māori (543 cases and 462 controls), while Western Polynesian comprised of Samoa, Tonga, Tuvalu, Niue and Tokelau (369 cases and 234 controls) [35]. A separate NZ Māori sample set of 124 cases and 50 controls is included within the Eastern Polynesian sample set data presented above. These participants were recruited in collaboration with Ngāti Porou Hauora Charitable Trust from the Ngāti Porou rohe (tribal territory) located in the East Coast (Tairāwhiti) region of the North Island of Aotearoa New Zealand.

\section{Genotyping}

Three SNPs were examined: $r s 2231142$, rs10011796 (both ABCG2) and rs11942223 (SLC2A9). Genotypes for the NZ gout cases and controls, and for the European and Australian gout cases were determined using either (a) Taqman ${ }^{\circ}$ assays (rs2231142: C_15854163_70; rs10011796: C_ 9510320_10; rs11942223: C_1216479_10; Applied Biosystems, Foster City, USA) on a Lightcycler 480 machine (Roche Applied Science, IN, USA) or (b) Illumina Infinium CoreExome v24 bead chips processed at the University of Queensland (Centre for Clinical Genomics). Bead chip genotypes were auto-clustered using GenomeStudio v2011.1 software (Illumina, San Diego, USA). The Illumina GenomeStudio best practice guidelines and quality control protocols of Guo et al. [36] were applied to these autoclustered genotypes to ensure final genotype calls were of the highest possible quality. SNP rs7442295 was identified as being in complete linkage disequilibrium with rs11942223 in European and East Asian populations using LDLink [37] and was used as a proxy on the bead chip for rs11942223. A total of 2940 samples were genotyped on both platforms for all 3 SNPs, with genotype concordance exceeding 99.8\%.

Publicly available genotype data for the ARIC, FHS, CARDIA and CHS participants were used. These genotypes were generated by the Affymetrix 6.0 platform (ARIC and CARDIA datasets), the combined Affymetrix $50 \mathrm{~K}$ and $500 \mathrm{~K}$ platform (the FHS dataset), and the Illumina Human CNV370v1 platform (the CHS dataset). Rs 2231142 was genotyped on the Affymetrix $50 \mathrm{~K}$ and $500 \mathrm{~K}$ platforms and imputed using IMPUTE2 using the 1000 Genomes Phase I haplotype reference panel in the ARIC, CARDIA and CHS sample sets. Similarly, rs10011796 (ABCG2) and rs11942223 (SLC2A9) were imputed in all four sample sets.

\section{Statistical analysis}

All analyses were performed using R v3.1.2 using RStudio 0.98. Deviation from Hardy-Weinberg equilibrium within each group (gout, HU controls and NU controls) was tested separately using the Haldane Exact test for
Hardy-Weinberg equilibrium $(\alpha=0.01)$ for each population and each SNP. Allelic association testing of ABCG2 rs 2231142 and rs10011796, and SLC2A9 rs11942223 for comparison, with gout and $\mathrm{HU}$ was performed using logistic regression. We analysed gout vs. all controls, NU controls vs. HU controls, and gout vs. HU controls. The SNPs were also tested for association with serum urate concentration at recruitment in combined NU and $\mathrm{HU}$ controls using linear regression. Association of each of the three variants with self-reported number of gout flares over a 12-month period was examined using linear regression. Analyses were adjusted by age, sex (except male-only analyses) and principal components (PCs) 1 to 10 (Polynesian sample sets only). For association testing of gout in the presence of $\mathrm{HU}$, analyses were additionally adjusted by highest recorded serum urate concentration. All Polynesian meta-analyses were performed in $\mathrm{R}$ using meta $\mathrm{v} 4.8-2$ [38], and an inversevariance fixed effect model unless otherwise stated.

Given the low linkage disequilibrium between $A B C G 2$ rs2231142 and rs10011796 in European and East Asian populations $\left(r^{2}=0.087\right.$ and 0.12 , respectively), genotypes were categorised as risk allele-positive or allele-negative for both SNPs, and association of rs2231142-rs10011796 genotype combinations were tested for gout vs. all controls, and gout vs. HU controls using logistic regression. Non-additive interaction between the two SNPs in determining the risk of gout was also examined, including an interaction term between rs2231142 and rs10011796 in the multivariate-adjusted logistic regression model.

\section{Results}

Relevant demographic, anthropomorphic and biochemical characteristics of the various sample sets are presented in Additional file 1. At recruitment urate levels were higher in the HU group than in the gout group in both European $(0.47$ vs $0.41 \mathrm{mmol} / \mathrm{L})$ and Polynesian $(0.48 \mathrm{vs} 0.43 \mathrm{mmol} / \mathrm{L})$. In both European and Polynesian, there was a preponderance of males in the gout (84.7 and $82.5 \%$, respectively) and HU sample sets (78.8 and $73.2 \%$ respectively) compared to NU ( 40.0 and $36.9 \%$, respectively). Given this, along with evidence that $A B C G 2$ rs2231142 has a stronger effect on urate and gout in males than females [13], male-only analyses were also done (Additional File 2), which yielded similar results.

The genotypes of all sample sets were in HardyWeinberg equilibrium $(P>0.01)$. ABCG2 SNPs $r s 2231142$ (Q141K) and rs 10011796 and, for comparison, the SLC2A9 SNP rs11942223 were tested for allelic association with (a) gout in the presence of HU (Table 1; gout vs. HU), (b) gout per se (Table 1; gout vs. all controls), (c) HU (Table 1; HU vs. NU) and, (d) serum urate levels in controls (Table 2). In European, the $\mathrm{T}$ allele of $r s 2231142$ (141K) was strongly associated with $\mathrm{HU}$ using $\mathrm{NU}$ controls $(\mathrm{OR}=1.56, P=$ 





Table 2 Association analysis of rs2231142, rs10011796 (ABCG2) and rs11942223 (SLC2A9) with serum urate at recruitment (mmol/L) in European and NZ Polynesian controls

\begin{tabular}{|c|c|c|c|c|c|c|}
\hline \multirow[t]{2}{*}{ SNP/allele } & \multicolumn{3}{|c|}{ Combined sex* } & \multicolumn{3}{|c|}{ Male only* } \\
\hline & $N$ & $\beta \mathrm{mmol} / \mathrm{L}$ (SE) & $P$ & $N$ & $\beta \mathrm{mmol} / \mathrm{L}$ (SE) & $P$ \\
\hline \multicolumn{7}{|l|}{ rs $2231142 / T$} \\
\hline European control & 13,982 & $0.017(1.5 E-03)$ & $8.9 E-30$ & 6514 & $0.020(2.2 \mathrm{E}-03)$ & $5.7 E-20$ \\
\hline WP control & 234 & $0.019(9.2 \mathrm{E}-03)$ & 0.035 & 134 & $0.027(0.011)$ & 0.017 \\
\hline EP control & 462 & $0.015(0.012)$ & 0.19 & 190 & $0.009(0.023)$ & 0.68 \\
\hline Polynesian meta-analysis & 696 & $0.018(7.2 E-03)$ & 0.014 & 324 & $0.024(0.010)$ & 0.019 \\
\hline \multicolumn{7}{|l|}{ rs10011796/T } \\
\hline European control & 14,349 & $0.006(9.2 \mathrm{E}-04)$ & 1.7E-10 & 6682 & $0.006(4.7 \mathrm{E}-03)$ & $1.5 E-06$ \\
\hline WP control & 234 & $0.006(8.5 \mathrm{E}-03)$ & 0.51 & 134 & $0.006(0.011)$ & 0.62 \\
\hline EP control & 462 & $0.005(5.0 \mathrm{E}-03)$ & 0.33 & 190 & $0.000(8.1 \mathrm{E}-03)$ & 0.99 \\
\hline Polynesian meta-analysis & 696 & $0.005(4.3 E-03)$ & 0.94 & 324 & $0.002(6.6 E-03)$ & 0.77 \\
\hline \multicolumn{7}{|l|}{ rs11942223/C } \\
\hline European control & 14,349 & $-0.024(1.1 \mathrm{E}-03)$ & $8.4 E-106$ & 6681 & $-0.017(1.6 \mathrm{E}-03)$ & $8.1 E-27$ \\
\hline WP control & 234 & $-0.021(0.023)$ & 0.38 & 134 & $-0.038(0.038)$ & 0.32 \\
\hline EP control & 462 & $-0.008(0.012)$ & 0.53 & 190 & $0.052(0.022)$ & 0.022 \\
\hline Polynesian meta-analysis^ & 696 & $-0.011(0.011)$ & 0.63 & 324 & $0.012(0.044)$ & 0.78 \\
\hline
\end{tabular}

*European sample set adjusted by age and sex (combined sex only). Polynesian sample sets additionally adjusted by PCs 1-10

$\wedge$ As the test for heterogeneity between Western Polynesian (WP) and Eastern Polynesian (EP) was significant $(p=0.043)$, a random effects model was used

$\left.1.7 \mathrm{E}^{-18}\right)$, and with gout when using $\mathrm{HU}$ controls $(\mathrm{OR}=$ $\left.1.85, P=3.8 \mathrm{E}^{-21}\right)$. In the Polynesian sample sets, there was no evidence for an effect of $r s 2231142$ in determining $\mathrm{HU}$ in Western Polynesian $(\mathrm{OR}=1.52, P=0.091)$ or Eastern Polynesian $(\mathrm{OR}=1.41, P=0.37)$ (Table 1$)$, with a Polynesian meta-analysis yielding $\mathrm{OR}_{\text {meta }}=1.49, P=0.057$. We note that the Polynesian ORs were similar to that in Europeans, suggesting that the non-significance may be due to reduced power of the Polynesian sample set. However, rs2231142 was associated by linear regression with serum urate levels in Polynesian (Table 2; $\beta_{\text {meta }}=0.018 \mathrm{mmol} / \mathrm{L}$, $P=0.014)$ with an effect size similar to European $(\beta=0.017$ $\left.\mathrm{mmol} / \mathrm{L}, P=8.9 \mathrm{E}^{-30}\right)$. In Polynesian, $r s 2231142$ was associated with the risk of gout compared to $\mathrm{HU}$ in Western Polynesian $(\mathrm{OR}=1.77, P=0.012)$, EP $(\mathrm{OR}=2.02, \quad P=$ $0.043)$, and the Polynesian meta-analysis $\left(\mathrm{OR}_{\text {meta }}=1.85\right.$, $P=1.3 \mathrm{E}^{-03}$ ) with effect sizes similar to that in Europeans (Table 1).

The strength of association of $A B C G 2$ rs 2231142 with gout in the presence of $\mathrm{HU}$ in European was significantly different to SLC2A9 rs $11942223\left(\mathrm{OR}_{\text {risk }}\right.$ allele $=1.85$ for rs2231142 compared to $\mathrm{OR}_{\text {risk allele }}=1.37$ for $r s 11942223$, $\left.P_{\mathrm{Het}}=2.1 \mathrm{E}^{-03}\right)$. In contrast, the effect sizes on $\mathrm{HU}$ in European were not significantly different $\left(\mathrm{OR}_{\text {risk allele }}=\right.$ 1.56 for $r s 2231142$ compared to $\mathrm{OR}_{\text {risk }}$ allele $=1.52$ for rs11942223, $\left.P_{\text {Het }}=0.64\right)$. In the Polynesian sample set, the minor allele of $r s 11942223$ was uncommon $(<5 \%$ in most groups) with no nominally significant $(P<0.05)$ associations detected in the three gout and $\mathrm{HU}$ analyses (Table 1).
To test the possibility that inclusion of both sexes in the analysis was influencing, the results a male-only analysis was done, which yielded similar data (Additional file 2).

ABCG2 rs10011796 displayed a similar pattern of association in Europeans as $r s 2231142$, albeit with a weaker effect size $\left(\mathrm{OR}=1.39, P=3.5 \mathrm{E}^{-11}\right.$ for gout vs. $\mathrm{HU}$, and $\mathrm{OR}=1.18$, $P=7.8 \mathrm{E}^{-07}$ for $\mathrm{HU}$ vs. NU). However, $r s 10011796$ was not significantly associated in any of the three comparisons (gout vs. HU, gout vs. all controls, $\mathrm{HU}$ vs. NU) in any of the Polynesian sample sets (all $P>0.06$ ) (Table 1).

The three SNPs of interest were tested for association with gout flare frequency in each sample set (Table 3). The ABCG2 rs $2231142 \mathrm{~T}$ allele was associated with an additional 2.54 and 2.16 self-reported flares per year in the WP and meta-analysed Polynesian sample sets (Table 3; $P=8.9 \mathrm{E}^{-03}$ and $P_{\text {meta }}=2.5 \mathrm{E}^{-03}$, respectively) but not in European $(P=0.97)$. Neither $r s 10011796$ nor $r s 11942223$ was associated with flare frequency in any sample set.

Non-additive interaction between rs2231142 and rs10011796 in determining the risk of gout was examined for gout vs. all controls, and gout vs. HU (Table 4). The interaction of $r s 2231142$ and rs10011796 was significant in European gout vs. all controls $\left(P=7.9 \mathrm{E}^{-03}\right)$ but did not reach significance in the gout vs. $\mathrm{HU}$ analysis $(P=0.062)$. There was no evidence for significant interaction in any of the Polynesian sample sets. Stratification by genotype groups (Table 5) revealed that the interaction was driven by a non-additive contribution to the risk of gout (gout vs. all controls) when the rs2231142 risk-positive genotype 
Table 3 Association analysis of rs2231142, rs10011796 (ABCG2) and rs11942223 (SLC2A9) gout risk alleles with the number of self-reported gout flares in the previous year by gout patients

\begin{tabular}{llll}
\hline SNP/risk allele & $N$ & $\beta(\mathrm{SE})^{*}$ & $P$ \\
\hline rs2231142/T & & & \\
European gout & 921 & $-0.019(0.479)$ & 0.97 \\
Western Polynesian gout & 359 & $2.54(0.965)$ & $8.9 E-03$ \\
Eastern Polynesian gout & 481 & $1.69(1.061)$ & 0.11 \\
$\quad$ Polynesian meta-analysis & 840 & $2.16(0.714)$ & $2.5 E-03$ \\
rs 10011796/T & & & \\
European gout & 920 & $0.29(0.396)$ & 0.47 \\
$\quad$ Western Polynesian gout & 359 & $0.46(0.982)$ & 0.64 \\
Eastern Polynesian gout & 481 & $-1.02(0.638)$ & 0.11 \\
Polynesian meta-analysis & 840 & $-0.58(0.535)$ & 0.28 \\
rs 11942223/T & & & \\
European gout & 924 & $-0.11(0.596)$ & 0.85 \\
$\quad$ Western Polynesian gout & 359 & $1.80(3.122)$ & 0.56 \\
Eastern Polynesian gout & 481 & $2.53(1.440)$ & 0.080 \\
Polynesian meta-analysis & 840 & $2.40(1.308)$ & 0.067 \\
\hline
\end{tabular}

*European sample set adjusted by age and sex. Polynesian sample sets additionally adjusted by PCs $1-10$

group (GT,TT) was combined with the rs10011796 risknegative genotype (CC). The ORs for this genotype combination were higher than the ORs for risk-positive genotypes at both SNPs (European OR = 3.78 vs. 3.37; Western Polynesian $\mathrm{OR}=4.81$ vs. 4.40; Eastern Polynesian $\mathrm{OR}=$ 2.88 vs. 2.45). The gout vs. HU controls analysis yielded similar findings in Europeans as using all controls, but with reduced ORs (Table 5). However, there was a strikingly high risk for gout in the $r s 2231142$ risk positive and rs10011796 risk negative category in Western Polynesian $\left(\mathrm{OR}=21.5, P=8.6 \times 10^{-3}\right)$.

\section{Discussion}

We report association of the ABCG2 rs2231142 141K (T) allele with gout in the presence of HU in European, Eastern and Western Polynesian sample sets. In all sample sets, the effect size was substantial $(\mathrm{OR}=1.77-2.02)$ (Table 1). These results are consistent with a role for $A B C G 2$ in the progression from $\mathrm{HU}$ to gout. This conclusion is supported by the association of $141 \mathrm{~K}$ with flare frequency in Polynesians $\left(P_{\text {meta }}=2.5 \mathrm{E}^{-03}\right)$ (Table 3). For $r s 10011796$, there was evidence for association with gout in the presence of $\mathrm{HU}$ and with HU in Europeans only. Stratification of genotypes by presence or absence of gout-risk allele in the HU vs gout analysis provides evidence for an epistatic interaction between rs2231142 and rs10011796 most notably in Western Polynesian (Table 5). The addition of the $141 \mathrm{~K}$ risk allele to the non-risk rs10011796 CC-genotype increased risk of gout for these individuals non-additively from 1.0 to 21.5 in the gout vs. HU analysis. We did observe an effect also for SLC2A9 rs11942223 in the gout vs HU comparison for Europeans $(\mathrm{OR}=1.37$ for risk allele); however, this was notably weaker than that for $A B C G 2$ rs2231142 (OR = 1.85; $\left.P_{\text {Het }}=0.0023\right)$.

It is increasingly clear that there is heterogeneity in the frequency of the pathogenic $141 \mathrm{~K}$ variant between the ancestrally defined Western Polynesian (Samoa, Tonga, Niue, Tokelau) and Eastern Polynesian (New Zealand Māori, Cook Island Māori) populations of New Zealand. Although the $\mathrm{T}$ allele has a similar gout risk effect size, it is fivefold more prevalent in Western Polynesian (Table 1) and will, therefore, have a greater impact on this population. It is also a known risk factor for tophus in the presence of gout in Western Polynesian (OR = 1.66) but not in Eastern Polynesian $(\mathrm{OR}=0.91)$ [39]. The striking interaction of the risk $\mathrm{T}$ allele of $r s 2231142$ with $r s 10011796$ in promoting gout in the presence of HU is observed in Western Polynesian but not Eastern Polynesian sample sets (Table 5). Finally, we found association of the $141 \mathrm{~K}$ allele with flare frequency in Western Polynesian but not Eastern Polynesian (Table 3). Collectively, at $A B C G 2$ at least, these findings emphasise the need to carefully account for ancestry in studies investigating the genetic causes of gout in the Polynesian populations of New Zealand.

There are parallels between ABCG2 141K and the important cystic fibrosis-causing gene variant, $\triangle \mathrm{F} 508$ in CFTR, also an ABC transporter. Both variants cause instability in the nucleotide binding domain of their respective proteins and can be corrected by small molecules [20, 23]. Accumulation of aggresomes is a feature of both ABCG2 141K and cystic fibrosis [40], indicative of impaired

Table 4 Interaction terms between rs2231142 and rs10011796 in determining risk of gout in European and NZ Polynesian sample sets

\begin{tabular}{|c|c|c|c|c|c|c|}
\hline \multirow[t]{2}{*}{ Sample Set } & \multicolumn{3}{|c|}{ Gout vs. All Controls* } & \multicolumn{3}{|c|}{ Gout vs. HU* } \\
\hline & $\bar{N}$ & $\mathrm{OR}_{\text {Interaction }}(95 \% \mathrm{Cl})$ & $P$ & $\bar{N}$ & $\mathrm{OR}_{\text {Interaction }}(95 \% \mathrm{Cl})$ & $P$ \\
\hline European & 15,559 & $0.61(0.43-0.88)$ & $7.9 E-03$ & 3956 & $0.65(0.41-1.02)$ & 0.062 \\
\hline Western Polynesian & 603 & $0.62(0.17-2.11)$ & 0.45 & 457 & $0.10(0.01-1.09)$ & 0.059 \\
\hline Eastern Polynesian & 1003 & $0.89(0.25-2.92)$ & 0.85 & 655 & $1.48(0.18-8.32)$ & 0.67 \\
\hline Polynesian meta-analysis & 1606 & $0.75(0.31-1.78)$ & 0.51 & 1112 & $0.54(0.13-2.32)$ & 0.41 \\
\hline
\end{tabular}

*European sample set adjusted by age and sex. Polynesian sample sets additionally adjusted by PCs 1-10 
Table 5 Risk of gout in rs2231142-rs10011796 genotype combinations classified by absence/presence of gout risk alleles

\begin{tabular}{|c|c|c|c|c|c|c|c|c|c|c|}
\hline \multicolumn{3}{|l|}{ Genotype } & \multicolumn{4}{|c|}{ Gout vs. All Controls* } & \multicolumn{4}{|c|}{ Gout vs. HU Controls* } \\
\hline Sample Set & rs $2231142 \wedge$ & rs10011796^ & $\begin{array}{l}\text { Controls } \\
N(\%)\end{array}$ & $\begin{array}{l}\text { Gout } \\
N(\%)\end{array}$ & OR $(95 \% \mathrm{Cl})$ & $P$ & $\begin{array}{l}\text { HU Controls } \\
N(\%)\end{array}$ & $\begin{array}{l}\text { Gout } \\
N(\%)\end{array}$ & OR $(95 \% \mathrm{Cl})$ & $P$ \\
\hline \multirow[t]{5}{*}{ European } & & & 13,981 & 1578 & & & 2378 & 1578 & & \\
\hline & GG & $\mathrm{CC}$ & 3996 (28.6) & $280(17.7)$ & 1.00 & - & $601(25.3)$ & $280(17.7)$ & 1.00 & - \\
\hline & GG & $\mathrm{CT}, \mathrm{TT}$ & 7193 (51.4) & $687(43.5)$ & $1.46(1.26-1.71)$ & $9.2 E-07$ & $1161(48.8)$ & $687(43.5)$ & $1.33(1.11-1.59)$ & $2.1 E-03$ \\
\hline & GT, TT & $\mathrm{CC}$ & $247(1.8)$ & $59(3.7)$ & $3.78(2.67-5.28)$ & $1.8 E-14$ & $53(2.2)$ & $59(3.7)$ & $2.60(1.70-3.98)$ & $9.9 E-06$ \\
\hline & GT, TT & $\mathrm{CT}, \mathrm{TT}$ & 2545 (18.2) & $552(35.0)$ & 3.37 (2.87-3.98) & $2.8 E-48$ & $563(23.7)$ & $552(35.0)$ & $2.24(1.85-2.73)$ & $5.8 E-16$ \\
\hline \multirow[t]{5}{*}{ WP } & & & 234 & 369 & & & 88 & 369 & & \\
\hline & GG & $\mathrm{CC}$ & $22(9.4)$ & $14(3.8)$ & 1.00 & - & $9(10.2)$ & $14(3.8)$ & 1.00 & \\
\hline & GG & $\mathrm{CT}, \mathrm{TT}$ & $110(47.0)$ & $82(22.2)$ & $1.47(0.63-3.54)$ & 0.38 & $39(44.3)$ & $82(22.2)$ & $2.39(0.81-6.98)$ & 0.11 \\
\hline & GT, TT & $\mathrm{CC}$ & $9(3.8)$ & $24(6.5)$ & $4.81(1.53-16.06)$ & $8.5 E-03$ & $1(1.1)$ & $24(6.5)$ & $21.52(3.05-449.83)$ & $8.6 E-03$ \\
\hline & GT, TT & $\mathrm{CT}, \mathrm{TT}$ & $93(39.7)$ & $249(67.5)$ & $4.40(1.92-10.33)$ & $5.1 E-04$ & $39(44.3)$ & $249(67.5)$ & $5.26(1.84-14.74)$ & $1.6 E-03$ \\
\hline \multirow[t]{5}{*}{ EP } & & & 462 & 541 & & & 114 & 541 & & \\
\hline & GG & $\mathrm{CC}$ & $77(16.7)$ & $72(13.3)$ & 1.00 & - & $16(14.0)$ & $72(13.3)$ & 1.00 & - \\
\hline & GG & $\mathrm{CT}, \mathrm{TT}$ & $339(73.4)$ & $362(66.9)$ & $0.96(0.63-1.46)$ & 0.85 & 85 (74.6) & $362(66.9)$ & $0.83(0.42-1.57)$ & 0.58 \\
\hline & GT, TT & $\mathrm{CC}$ & $8(1.7)$ & $21(3.9)$ & $2.88(0.98-9.25)$ & 0.064 & $2(1.8)$ & $21(3.9)$ & $1.44(0.31-10.58)$ & 0.67 \\
\hline & GT, TT & $\mathrm{CT}, \mathrm{TT}$ & $38(8.2)$ & $86(15.9)$ & $2.45(1.36-4.47)$ & $3.2 E-03$ & $11(9.6)$ & $86(15.9)$ & $1.78(0.72-4.52)$ & 0.22 \\
\hline
\end{tabular}

*European sample set adjusted by age and sex. Polynesian sample sets additionally adjusted by PCs 1-10

$\wedge$ The T allele (presence highlighted in bold) is the gout risk allele in European for both SNPs

and/or inadequate protein degradation. Dysfunctional autophagosome clearance in cystic fibrosis leads to a hyperinflammatory state in which there is increased reactive oxygen species and impaired autophagy. This activates the NLRP3 inflammasome [41]. In addition, there is accumulation of p62, a protein that regulates aggresome formation by delivering ubiquitinated proteins for degradation by autophagy, resulting in increased IL- $1 \beta$ production by promoting cleavage of pro-caspase- 1 to caspase-1 [42]. The IL$1 \beta$ produced further increases p62 levels [40] resulting in defective autophagy in cystic fibrosis via accumulation of misfolded proteins in aggresomes. Reducing p62 levels allows localization of $\triangle \mathrm{F} 508 \mathrm{CFTR}$ to the cell surface where it can function [40]. In gout, MSU crystals impair proteasomal degradation causing increased expression of p62 [42], and it is likely that proteasomal degradation is impaired in the presence of the $141 \mathrm{~K}$ variant as evidenced by the formation of aggresomes [23]. ABCG2 promotes autophagy in cancer cell lines exposed to stressors such as nutrient deprivation [43], although the ability of the $141 \mathrm{~K}$ allele to impair autophagy is not yet established. It is possible that defective autophagy resulting from the $141 \mathrm{~K}$ variant could lead to increased IL-1 $\beta$ signalling, since autophagy normally allows for negative feedback regulation of IL-1 $\beta$ production via degradation of the NLRP3 inflammasome [44]. Autophagy is necessary for formation of neutrophil extracellular traps that attenuate the inflammatory response to MSU crystals [45]. Future studies that investigate and compare IL-1 $\beta$ production in response to MSU and autophagy in cells with the different $141 \mathrm{Q}$ and $141 \mathrm{~K}$ alleles would be illuminating.

The molecular mechanism driving the non-additive interaction between ABCG2 SNPs rs2231142 and rs10011796 is unclear. Given that rs10011796 is a noncoding intronic variant outside any known Encode regulatory motif features (www.encodeproject.org), it is likely that rs10011796 is in linkage disequilibrium with the causal variant, rather than the causal variant itself, although other intronic variants in $A B C G 2$ have been associated with ABCG2 expression [46, 47]. The majority of common phenotype associations identified by GWAS are expression quantitative trait loci [48], influencing gene expression and transcript stability, and these variants can therefore modify the penetrance of coding variants [49]. Thus, it is reasonable to hypothesise that rs10011796 marks an effect that influences gene expression. This is consistent with the presence of an expression QTL (regulatory) effect independent of $r s 2231142$ in the ABCG2 urate GWAS signal [47]. The rs10011796 $\mathrm{C}$-allele (that associates with reduced serum urate and risk of gout) does associate with reduced $A B C G 2$ and increased PPM1K-DT (a long non-coding RNA $100 \mathrm{~kb}$ downstream of $A B C G 2$ ) expression (www.gtex.org). How rs10011796 (or more likely a variant in linkage disequilibrium) could synergise with rs2231142 to amplify the risk of gout is unclear. However, it has previously been reported that a urate-associated variant at the $M A F$ locus influences the expression of MAF via a long non- 
coding RNA [50]. It is possible that in Western Polynesian people with $\mathrm{HU}$, the combination of the $141 \mathrm{~K}$ risk allele with the rs10011796 CC-genotype has an epistatic effect where an altered amount of $141 \mathrm{~K}$ is internalised, disrupting important stoichiometric relationships and promoting gouty inflammation. Finally, it is interesting to note that local epistatic interactions have also been reported at $S L C 2 A 9$ in the control of urate levels [51].

In addition to the common Q141K variant, there are numerous other uncommon and rare missense variants in ABCG2, mostly detected by resequencing ABCG2 exons in people with gout. These variants tend, as does $141 \mathrm{~K}$, to reduce the urate transport ability of ABCG2 [52]; they associate with gout [52, 53] and, including $141 \mathrm{~K}$, associate with an earlier age-of-onset of gout [52, 54]. The effect size on gout is similar to that of $141 \mathrm{~K}-$ increasing risk two to threefold [53]. It is possible that the rare and uncommon variants also contribute to the progression from HU to gout; however, testing this hypothesis will require very large datasets. Of significance for the study of the pathogenesis of gout is the possibility that genetic variation in other genes contribute both to $\mathrm{HU}$ and the progression from $\mathrm{HU}$ to gout. In our data, there was a suggestion that $S L C 2 A 9$ could be one such gene.

\section{Conclusion}

We provide genetic epidemiological evidence supporting a role for ABCG2 $141 \mathrm{~K}$ in the progression from HU to gout, additional to its role in promoting $\mathrm{HU}$. The variant may promote a hyper-inflammatory state akin to that observed with the cystic fibrosis gene, CFTR $\triangle \mathrm{F} 508$, featuring defective autophagy, formation of aggresomes, and activation of the NLPR3 inflammasome. An ABCG2 genotype combination (rs2231142-rs10011796) confers especially high risk for gout in Polynesian people with hyperuricaemia.

\section{Supplementary information}

Supplementary information accompanies this paper at (https://doi.org/10. 1186/s13075-020-2136-z)

Additional file 1: Table S1. Characteristics of sample sets. (DOCX $20 \mathrm{~kb}$ )

Additional file 2: Table S2. Association analysis of rs2231142, rs 10011796 (ABCG2) and rs11942223 (SLC2A9) in European and NZ Polynesian sample sets with the risk of gout in males only. (DOCX $29 \mathrm{~kb}$ )

\footnotetext{
Abbreviations

ABCG2: ATP-binding cassette subfamily G member 2; ARIC: Atherosclerosis Risk in Communities; CARDIA: Coronary Artery Risk Development in Young Adults; CHS: Cardiovascular Health Study; CTFR: Cystic fibrosis transmembrane conductance regulator; EP: Eastern Polynesian; FHS: Framingham Heart Study; GWAS: Genome-wide association study; HU: Hyperuricemia; IL-1 1 : Interleukin-1 $\beta$; MSU: Monosodium urate; NLRP3: NLR family pyrin domain containing 3; NU: Normouricemia; NZ: New Zealand; OR: Odds ratio; PC: Principal component; SLC2A9: Solute carrier
}

family 2 member 9; SNP: Single nucleotide polymorphism; WP: Western Polynesian

\section{Acknowledgements}

The authors would like to thank Jordyn Allan, Jill Drake, Roddi Laurence, Christopher Franklin, Meaghan House and Gabrielle Sexton for recruitment. Matthew Brown, Linda Bradbury and The Arthritis Genomics Recruitment Initiative in Australia network are acknowledged. The European Crystal Network [55], formed after the first European Crystal Workshop in Paris, March 2010 (Prof Frédéric Lioté, Paris, and Prof Alexander So, Lausanne, convenors) is also acknowledged. The Atherosclerosis Risk in Communities and Framingham Heart study analyses (project \#834) were approved by the relevant Database of Genotype and Phenotype (dbGaP; www.ncbi.nim.nih/ gov/dbgap) Data Access Committees. The Atherosclerosis Risk in

Communities Study is carried out as a collaborative study supported by National Heart, Lung, and Blood Institute contracts N01-HC-55015, N01-HC55016, N01-HC-55018, N01-HC-55019, N01-HC-55020, N01-HC-55021, N01-HC55022, R01HL087641, R01HL59367 and R01HL086694; National Human Genome Research Institute contract U01HG004402; and National Institutes of Health contract HHSN268200625226C. LABJ was supported by a Competitiveness Operational Program Grant of the Romanian Ministry of European Funds (HINT, ID P_37_762; MySMIS 103587).

The authors thank the staff and participants of the ARIC study for their important contributions. Infrastructure was partly supported by Grant Number UL1RR025005, a component of the National Institutes of Health and $\mathrm{NIH}$ Roadmap for Medical Research. The Framingham Heart Study and the Framingham SHARe project are conducted and supported by the National Heart, Lung, and Blood Institute (NHLBI) in collaboration with Boston University. The Framingham SHARe data used for the analyses described in this manuscript were obtained through dbGaP. This manuscript was not prepared in collaboration with investigators of the Framingham Heart Study and does not necessarily reflect the opinions or views of the Framingham Heart Study, Boston University, or the NHLBI.

\section{Funding}

The study was funded by the Health Research Council of New Zealand (grant 14/527). The funder had no role in the design, execution and reporting of the study.

\section{Availability of data and materials}

Owing to consent restrictions, it is not possible to make the New Zealand, Australian and European gout-control datasets publicly available, although they may be obtainable from the corresponding author under appropriate request. The ARIC, FHS, CHS and CARDIA datasets are publicly available at the Database of Genotype and Phenotype.

\section{Authors' contributions}

RW, AJP and TRM contributed to the study design, analysed and interpreted the data and drafted the manuscript. RKT, TJM and MC contributed to data analysis, interpretation and the manuscript. PR, A-KT, MJ, LABJ, TLJ, AS, JHH, LKT and ND contributed to data collection and interpretation and contributed to the manuscript draft. All authors read and approved the final manuscript.

\section{Ethics approval and consent to participate}

In New Zealand, the New Zealand Multi-Region Ethics Committee (MEC/05/ 10/130) and the Northern Y Region Health Research Ethics Committee (Ngāti Porou Hauora Charitable Trust study; NTY07/07/074) provided ethical approval for the study. The following institutional committees in Europe and Australia also granted ethical approval: Research Ethics Committee, University of New South Wales; Ethikkommission, Technische Universität Dresden (EK 8012012); South East Scotland Research Ethics Committee (04/S1102/41); Commission Cantonale D'éthique de la Recherche sur l'être Humain, Université de Lausanne; Commissie Mensgebonden Onderzoek regio Arnhem Nijmegen. All subjects gave written informed consent. The Database of Genotype and Phenotype (www.ncbi.nlm.nih.gov/gap) approval number was \#834 for accessing data from the ARIC, FHS, CARDIA and CHS studies. 


\section{Competing interests}

The authors declare that they have no competing interests.

\section{Author details}

'Department of Biochemistry, University of Otago, Box 56, Dunedin, New Zealand. ${ }^{2}$ Rheumatic Diseases Unit, Institute of Genetics and Molecular Medicine, University of Edinburgh, Edinburgh, UK. ${ }^{3}$ Department of Rheumatology, University Clinic "Carl-Gustav-Carus", Dresden, Germany. ${ }^{4}$ Department of Rheumatology, VieCuri Medical Center, Venlo, The Netherlands. ${ }^{5}$ Department of Internal Medicine and Radboud Institute of Molecular Life Science, Radboud University Medical Center, Nijmegen, The Netherlands. ${ }^{6}$ Department of Medical Genetics, Iuliu Hatieganu University of Medicine and Pharmacy, Cluj-Napoca, Romania. ${ }^{7}$ Laboratory of Rheumatology, University of Lausanne, CHUV, Nestlé 05-5029, 1011 Lausanne, Switzerland. ${ }^{8}$ Ngāti Porou Hauora Charitable Trust, Te Puia Springs, Tairāwhiti, New Zealand. ${ }^{9}$ Department of Medicine, University of Otago, Christchurch, PO Box 4345, Christchurch, New Zealand. ${ }^{10}$ Department of Medicine, University of Auckland, Auckland, New Zealand.

Received: 3 January 2020 Accepted: 20 February 2020 Published online: 12 March 2020

\section{References}

1. Dalbeth N, Merriman TR, Stamp LK. Gout Lancet. 2016;388:2039-52.

2. Nakatochi M, Kanai M, Nakayama A, Hishida A, Kawamura Y, Ichihara S, et al. Genome-wide meta-analysis identifies multiple novel loci associated with serum uric acid levels in Japanese individuals. Comm Biol. 2019;2:115.

3. Tin A, Marten J, Kuhns VLH, Li Y, Wuttke M, Kirsten H, et al. Target genes, variants, tissues and transcriptional pathways influencing human serum urate levels. Nat Genet. 2019;51:1459-74.

4. Köttgen A, Albrecht E, Teumer A, Vitart V, Krumsiek J, Hundertmark C, et al Genome-wide association analyses identify 18 new loci associated with serum urate concentrations. Nat Genet. 2013;45:145-54.

5. Phipps-Green A, Merriman M, Topless R, Altaf S, Montgomery G, Franklin C, et al. Twenty-eight loci that influence serum urate levels: analysis of association with gout. Ann Rheum Dis. 2014;75:124-30.

6. Dalbeth N, Phipps-Green A, Frampton C, Neogi T, Taylor WJ, Merriman TR Relationship between serum urate concentration and clinically evident incident gout: an individual participant data analysis. Ann Rheum Dis. 2018; 77:1048-52.

7. Busso N, So A. Mechanisms of inflammation in gout. Arthritis Res Ther. 2010; 12:206.

8. Dinarello CA. How interleukin-1 $\beta$ induces gouty arthritis. Arthritis Rheum 2010;62:3140-4.

9. Major TJ, Dalbeth N, Stahl EA, Merriman TR. An update on the genetics of hyperuricaemia and gout. Nat Rev Rheumatol. 2018;14:341-53.

10. McKinney C, Stamp LK, Dalbeth N, Topless RK, Day RO, Kannangara DR, et al. Multiplicative interaction of functional inflammasome genetic variants in determining the risk of gout. Arthritis Res Ther. 2015;17:288.

11. Qing YF, Zhou JG, Zhang QB, Wang DS, Li M, Yang QB, et al. Association of TLR4 gene rs 2149356 polymorphism with primary gouty arthritis in a casecontrol study. PLoS One. 2013;8:e64845.

12. Rasheed H, McKinney C, Stamp LK, Dalbeth N, Topless RK, Day R, et al. The toll-like receptor 4 (TLR4) variant rs2149356 and risk of gout in European and Polynesian sample sets. PLoS One. 2016;11:e0147939.

13. Dehghan A, Kottgen A, Yang Q, Hwang SJ, Kao WL, Rivadeneira F, et al. Association of three genetic loci with uric acid concentration and risk of gout: a genome-wide association study. Lancet. 2008;372:1953-61.

14. Cleophas M, Joosten L, Stamp L, Dalbeth N, Woodward O, Merriman TR ABCG2 polymorphisms in gout: insights into disease susceptibility and treatment approaches. Pharmacogenomics Pers Med. 2017;10:129-42.

15. Hoque KM, Woodward OM. New mouse model of gout risk variant, $A B C G 2$ Q141K, reveals unexpectedly severe molecular and functional defect in ABCG2-mediated intestinal uric acid secretion. Arthritis Rheumatol. 2017; 69(S10):4187.

16. Ichida K, Matsuo H, Takada T, Nakayama A, Murakami K, Shimizu T, et al. Decreased extra-renal urate excretion is a common cause of hyperuricemia. Nat Commun. 2012:3:764

17. Wen C, Yee S, Liang X, Hoffmann T, Kvale M, Banda Y, et al. Genome-wide association study identifies ABCG2 (BCRP) as an allopurinol transporter and a determinant of drug response. Clin Pharmacol Therapeut. 2015;97:518-25.
18. Roberts RL, Wallace MC, Phipps-Green AJ, Topless R, Drake JM, Tan P, et al. ABCG2 loss-of-function polymorphism predicts poor response to allopurinol in patients with gout. Pharmacogenomics J. 2015;17:201-3.

19. Wallace MC, Roberts RL, Nanavati P, Miner JN, Dalbeth $N$, Topless $R$, et al. Association between ABCG2 rs2231142 and poor response to allopurinol: replication and meta-analysis. Rheumatology (Oxford). 2018;57:656-60.

20. Woodward OM, Tukaye DN, Cui JM, Greenwell P, Constantoulakis LM, Parker BS, et al. Gout-causing Q141K mutation in ABCG2 leads to instability of the nucleotide-binding domain and can be corrected with small molecules. Proc Natl Acad Sci U S A. 2013;110:5223-8.

21. Woodward OM, Kottgen A, Coresh J, Boerwinkle E, Guggino WB, Kottgen M Identification of a urate transporter, $A B C G 2$, with a common functional polymorphism causing gout. Proc Natl Acad Sci U S A. 2009;106:10338-42.

22. Sarankó H, Tordai H, Telbisz Á, Özvegy-Laczka C, Erdős G, Sarkadi B, et al. Effects of the gout-causing Q141K polymorphism and a CFTR $\Delta$ F508 mimicking mutation on the processing and stability of the $A B C G 2$ protein. Bioc Biophys Res Comm. 2013;437:140-5.

23. Basseville A, Tamaki A, lerano C, Trostel S, Ward Y, Robey RW, et al. Histone deacetylase inhibitors influence chemotherapy transport by modulating expression and trafficking of a common polymorphic variant of the ABCG2 efflux transporter. Cancer Res. 2012;72:3642-51.

24. Johnston JA, Ward CL, Kopito RR. Aggresomes: a cellular response to misfolded proteins. J Cell Biol. 1998;143:1883-98.

25. Lin Y-H, Chang H-M, Chang F-P, Shen C-R, Liu C-L, Mao W-Y, et al. Protoporphyrin IX accumulation disrupts mitochondrial dynamics and function in ABCG2-deficient hepatocytes. FEBS Lett. 2013;587:3202-9.

26. Gosling AL, Boocock J, Dalbeth N, Harré Hindmarsh J, Stamp LK, Stahl EA, et al. Mitochondrial genetic variation and gout in Māori and Pacific people living in Aotearoa New Zealand. Ann Rheum Dis. 2018;77:571-8.

27. Abdelaziz DH, Khalil H, Cormet-Boyaka E, Amer AO. The cooperation between the autophagy machinery and the inflammasome to implement an appropriate innate immune response: do they regulate each other? Immunol Rev. 2015;265:194-204.

28. Chen C-J, Tseng C-C, Yen J-H, Chang J-G, Chou W-C, Chu H-W, et al. ABCG2 contributes to the development of gout and hyperuricemia in a genomewide association study. Sci Rep. 2018;8:3137.

29. Kawamura Y, Nakaoka H, Nakayama A, Okada Y, Yamamoto K, Higashino T, et al. Genome-wide association study revealed novel loci which aggravate asymptomatic hyperuricaemia into gout. Ann Rheum Dis. 2019;78:1430-7.

30. Li C, Li Z, Liu S, Wang C, Han L, Cui L, et al. Genome-wide association analysis identifies three new risk loci for gout arthritis in Han Chinese. Nat Commun. 2015;6:7041

31. Okada Y, Sim X, Go MJ, Wu J-Y, Gu D, Takeuchi F, et al. Meta-analysis identifies multiple loci associated with kidney function-related traits in east Asian populations. Nat Genet. 2012:44:904-9.

32. Urano W, Taniguchi A, Inoue E, Sekita C, Ichikawa N, Koseki Y, et al. Effect of genetic polymorphisms on development of gout. J Rheumatol. 2013;40: 1374-8

33. Wallace SL, Robinson H, Masi AT, Decker JL, McCarty DJ, Yu TF. Preliminary criteria for the classification of the acute arthritis of primary gout. Arthritis Rheum. 1977:20:895-900.

34. Krishnan M, Major TJ, Topless RK, Dewes O, Yu L, Thompson JMD, et al. Discordant association of the CREBRF rs373863828 minor allele with increased body mass index and protection from type 2 diabetes in Mãori and Pacific (Polynesian) people living in Aotearoa New Zealand. Diabetologia. 2018;61:1603-13.

35. Phipps-Green AJ, Hollis-Moffatt J, Dalbeth N, Merriman ME, Topless R, Gow PJ, et al. A strong role for the ABCG2 gene in susceptibility to gout in New Zealand Pacific Island and Caucasian, but not Maori, case and control sample sets. Hum Mol Genet. 2010;19:4813-9.

36. Guo $Y$, He J, Zhao S, Wu H, Zhong $X$, Sheng Q, et al. Illumina human exome genotyping array clustering and quality control. Nat Prot. 2014;9:2643-62.

37. Machiela MJ, Chanock SJ. LDlink: a web-based application for exploring population-specific haplotype structure and linking correlated alleles of possible functional variants. Bioinformatics. 2015;31:3555-7.

38. Schwarzer G, Carpenter JR, Rücker G. Meta-analysis with R: springer; 2015.

39. He W, Phipps-Green A, Stamp LK, Merriman TR, Dalbeth N. Populationspecific association between ABCG2 variants and tophaceous disease in people with gout. Arthritis Res Ther. 2017;19:43.

40. Luciani A, Villella VR, Esposito S, Brunetti-Pierri N, Medina D, Settembre C, et al. Defective CFTR induces aggresome formation and lung inflammation 
in cystic fibrosis through ROS-mediated autophagy inhibition. Nat Cell Biol. 2010;12:863-75

41. Mayer ML, Blohmke CJ, Falsafi R, Fjell CD, Madera L, Turvey SE, et al. Rescue of dysfunctional autophagy attenuates hyperinflammatory responses from cystic fibrosis cells. J Immunol. 2013;190:1227-38.

42. Choe J-Y, Jung H-Y, Park K-Y, Kim S-K. Enhanced p62 expression through impaired proteasomal degradation is involved in caspase-1 activation in monosodium urate crystal-induced interleukin-1 $\beta$ expression. Rheumatology (Oxford). 2014;53:1043-53.

43. Ding R, Jin S, Pabon K, Scotto KW. A role for ABCG2 beyond drug transport: regulation of autophagy. Autophagy. 2016;12:737-51.

44. Shi C-S, Shenderov K, Huang N-N, Kabat J, Abu-Asab M, Fitzgerald KA, et al. Activation of autophagy by inflammatory signals limits IL-1 [beta] production by targeting ubiquitinated inflammasomes for destruction. Nat Immunol. 2012:13:255-63.

45. Schauer C, Janko C, Munoz LE, Zhao Y, Kienhofer D, Frey B, et al. Aggregated neutrophil extracellular traps limit inflammation by degrading cytokines and chemokines. Nat Med. 2014;20:511-7.

46. Poonkuzhali B, Lamba J, Strom S, Sparreboom A, Thummel K, Watkins P, et al. Association of breast cancer resistance protein/ABCG2 phenotypes and novel promoter and intron 1 single nucleotide polymorphisms. Drug Metab Disposition. 2008:36:780-95.

47. Boocock J, Leask M, Okada Y, Matsuo H, Kawamura Y, Shi Y, et al. Genomic dissection of 43 serum urate-associated loci provides multiple insights into molecular mechanisms of urate control. Hum Mol Genet. 2020; https://doi. org/10.1093/hmg/ddaa013

48. Ardlie KG, Deluca DS, Segrè AV, Sullivan TJ, Young TR, Gelfand ET, et al. The genotype-tissue expression (GTEx) pilot analysis: multitissue gene regulation in humans. Science. 2015;348:648-60.

49. Castel SE, Cervera A, Mohammadi P, Aguet F, Reverter F, Wolman A, et al. Modified penetrance of coding variants by cis-regulatory variation contributes to disease risk. Nat Genet. 2018;50:1327-34.

50. Leask M, Dowdle A, Salvesen H, Topless R, Fadason T, Wei W, et al. Functional urate-associated genetic variants influence expression of lincRNAs LINC01229 and MAFTRR. Front Physiol. 2019;9:733.

51. Wei W-H, Guo Y, Kindt AS, Merriman TR, Semple CA, Wang K, et al. Abundant local interactions in the $4 \mathrm{p} 16.1$ region suggest functional mechanisms underlying SLC2A9 associations with human serum uric acid. Hum Mol Genet. 2014;23:5061-8.

52. Stiburkova B, Pavelcova K, Zavada J, Petru L, Simek P, Cepek P, et al. Functional non-synonymous variants of $A B C G 2$ and gout risk. Rheumatology (Oxford). 2017;56:1982-92.

53. Higashino T, Takada T, Nakaoka H, Toyoda Y, Stiburkova B, Miyata H, et al. Multiple common and rare variants of ABCG2 cause gout. RMD Open. 2017; 3:e000464.

54. Zaidi F, Narang RK, Phipps-Green A, Gamble GG, Tausche A-K, So A, et al. Systematic genetic analysis of early-onset gout: $A B C G 2$ is the only associated locus. Rheumatology (Oxford). 2020; https://doi.org/10.1093/ rheumatology/kez685.

55. Liote F, Merriman T, Nasi S, So A. 4th European Crystal Network meeting Paris 8-9th March 2013. Arthritis Res Ther. 2013;15:304.

\section{Publisher's Note}

Springer Nature remains neutral with regard to jurisdictional claims in published maps and institutional affiliations.

\section{Ready to submit your research? Choose BMC and benefit from}

- fast, convenient online submission

- thorough peer review by experienced researchers in your field

- rapid publication on acceptance

- support for research data, including large and complex data types

- gold Open Access which fosters wider collaboration and increased citations

- maximum visibility for your research: over $100 \mathrm{M}$ website views per year

At BMC, research is always in progress.

Learn more biomedcentral.com/submissions 